\title{
Commentary: Adverse Childhood Experiences and Risk for Suicidal Behavior in Male Iraq and Afghanistan Veterans Seeking PTSD Treatment
}

\begin{abstract}
Leo Sher ${ }^{1,2 *+}$
1 James J. Peters Veterans' Administration Medical Center, Bronx, NY, USA, ${ }^{2}$ Icahn School of Medicine at Mount Sinai, New York, NY, USA
\end{abstract}

Keywords: adverse childhood experience, veteran, posttraumatic stress disorder, suicidal behavior, men's mental health

\section{A commentary on}

Adverse childhood experiences and risk for suicidal behavior in male Iraq and Afghanistan Veterans seeking PTSD treatment

by Carroll TD, Currier JM, McCormick WH, Drescher KD. Psychol Trauma (2017). doi:10.1037/ tra0000250

The authors of a recently published article entitled, "Adverse childhood experiences and risk for suicidal behavior in male Iraq and Afghanistan veterans seeking PTSD treatment” by Carroll et al. (1) examined a range of adverse childhood experiences (ACEs) among Iraq/Afghanistan veterans with combat-related posttraumatic stress disorder (PTSD). The researchers found that the majority of veterans had experienced multiple types of adversities during childhood and/or adolescence. More than $80 \%$ of veterans reported experiencing at least one childhood trauma or adversity. About $40 \%$ of study participants endorsed four or more childhood traumas or adversities. Veterans who reported physical neglect as a child were significantly more likely to report a history of attempting suicide. It is important to note that studies of civilian populations suggest that ACEs are very strong correlates of adulthood suicide risk (2-4).

Research on psychiatric disorders and suicide risk among active duty personnel and military veterans tends to focus on traumas related to the military service (5-7). However, a focus on service-related traumas does not provide a complete picture. The observations by Carroll et al. (1) are consistent with reports that pre-military experiences such as adversity in childhood play an important role in post-deployment mental health (7-9). For example, Van Voorhees et al. (9) studied about 1,300 veterans and active duty soldiers to examine the link of childhood abuse with adult PTSD after taking into account combat experience. Forty percent of the sample reported at least one childhood traumatic event. The authors observed that ACE and adult combat experience independently influenced PTSD symptomatology.

The results of studies by Blosnich et al. (10) and Afifi et al. (11) indicate that the military service may be a way for some people to replace dysfunctional home environments with more structured and directive environments. It is worth noting that there may be other reasons why people with a history of ACE may seek a military environment later in life. Blosnich et al. (10) compared the prevalence of childhood adversities among persons with and without a history of military service in the United States. They used the ACE inventory to assess 11 negative experiences before the age of 18 years. In the all-volunteer era (since 1973), men with a history of military service had a higher prevalence of ACEs in all 11 categories than men who did not serve in the military. A similar observation was made by 
Afifi et al. (11) who compared child abuse exposure in Canadian Armed Forces personnel and in the Canadian general population. They found that "individuals with a child abuse history may be more likely to enter the military, and child abuse exposure may increase the likelihood of suicide-related outcomes." It has been proposed that military enlistment among survivors of childhood adversities may be a sign of resilience and that the structure, training, and camaraderie of the military strengthen resilience among some survivors of childhood adversities (7). It is important to note that a study by Woodruff et al. (12) showed that most people who enlist in the United States Military do so for positive motives including patriotism, altruism, and self-improvement.

There are a lot of research observations of the effects of ACE on the psychobiological development of children and adolescents. Considerable evidence suggests that the brain development of children is likely to be affected in by their ACE (13-21). Early stress leads to an ongoing dysregulation of the hypothalamicpituitary-adrenal axis stress response system $(16-19,22)$. It has been proposed that the stress response system can either become chronically overactivated or underresponsive (16-18, 22, 23). Neuropsychological studies frequently show that children who have experienced ACE have cognitive problems in one or more areas, when compared to children who haven't experienced these adversities $(14,17,18,24)$. Many children that experience adversity develop difficulties related to learning, memory, and attention $(13,24-27)$. There is also evidence that social and emotional information is dealt with in a different way among persons with a history of ACE in comparison to individuals without a history of ACE $(16-18,28)$. Executive function difficulties can also develop as a result of $\operatorname{ACE}(18,29,30)$. The psychobiological development of individuals with ACE may determine their future life choices including the decision whether or not to join the military.

Military service may subject individuals with a history of trauma to additional trauma such as combat, which may additively

\section{REFERENCES}

1. Carroll TD, Currier JM, McCormick WH, Drescher KD. Adverse childhood experiences and risk for suicidal behavior in male Iraq and Afghanistan Veterans seeking PTSD treatment. Psychol Trauma (2017). doi:10.1037/ tra0000250

2. Brodsky BS, Stanley B. Adverse childhood experiences and suicidal behavior. Psychiatr Clin North Am (2008) 31(2):223-35. doi:10.1016/j. psc.2008.02.002

3. Miller AB, Esposito-Smythers C, Weismoore JT, Renshaw KD. The relation between child maltreatment and adolescent suicidal behavior: a systematic review and critical examination of the literature. Clin Child Fam Psychol Rev (2013) 16(2):146-72. doi:10.1007/s10567-013-0131-5

4. Makhija N, Sher L. Childhood abuse, adult alcohol use disorders and suicidal behaviour. QJM (2007) 100(5):305-9. doi:10.1093/qjmed/hcm024

5. LeardMann CA, Powell TM, Smith TC, Bell MR, Smith B, Boyko EJ, et al. Risk factors associated with suicide in current and former US military personnel. JAMA (2013) 310(5):496-506. doi:10.1001/jama.2013.65164

6. Bryan CJ, Griffith JH, Pace BT, Hinkson K, Bryan AO, Clemans TA, et al. Combat exposure and risk for suicidal thoughts and behaviors among military personnel and Veterans: a systematic review and meta-analysis. Suicide Life Threat Behav (2015) 45(5):633-49. doi:10.1111/sltb.12163

7. Blosnich JR, Bossarte RM. Childhood abuse and military experience-important information to better serve those who have served. JAMA Psychiatry (2016) 73(3):195-6. doi:10.1001/jamapsychiatry.2015.2736 increase risks of psychiatric disorders and suicidal behavior. If some military recruits have trauma-related psychological abnormalities that predispose to psychiatric disorders when they enter the military, then we have to seriously question the screening that goes into allowing persons to enter the military (31). Possibly, some individuals who were significantly traumatized by ACE and have psychiatric symptoms should be given non-combat assignments.

It is important to address early trauma histories in addition to more recent traumatic experiences because the psychobiological impact of early trauma is different from psychobiological effects of trauma during adulthood $(32,33)$. Studies have shown that a history of ACE is associated with poor response to treatment in patients with psychiatric disorders (34-36). Mental and nonmental health professionals who treat post-deployed service members should not only assess the seriousness of combat exposure but also childhood adversities to provide appropriate psychiatric treatment and to better understand psychiatric outcomes. Management of individuals with a history of ACE should include psychotherapeutic and pharmacological treatment of psychiatric disorders $(37,38)$. The aims of psychotherapy should include handling the disclosure of ACE in an open and empathic way, enhancing the patient's sense of safety, helping patients to decrease current life stress, and improve their social support.

Clinicians, researchers, and health policy makers should work to reduce the stigma of revealing ACE and apportion funds for epidemiologic studies and the development of new treatment modalities to tackle problems related to ACE among military personnel and veterans (7).

\section{AUTHOR CONTRIBUTIONS}

The author confirms being the sole contributor of this work and approved it for publication.

8. McGuinness TM, Waldrop JR. Adverse childhood experiences and the mental health of Veterans. J Psychosoc Nurs Ment Health Serv (2015) 53(6):23-6. doi:10.3928/02793695-20150527-55

9. Van Voorhees EE, Dedert EA, Calhoun PS, Brancu M, Runnals J, Beckham JC, et al. Childhood trauma exposure in Iraq and Afghanistan war era Veterans: implications for posttraumatic stress disorder symptoms and adult functional social support. Child Abuse Negl (2012) 36:423-32. doi:10.1016/j. chiabu.2012.03.004

10. Blosnich JR, Dichter ME, Cerulli C, Batten SV, Bossarte RM. Disparities in adverse childhood experiences among individuals with a history of military service. JAMA Psychiatry (2014) 71(9):1041-8. doi:10.1001/ jamapsychiatry.2014.724

11. Afifi TO, Taillieu T, Zamorski MA, Turner S, Cheung K, Sareen J. Association of child abuse exposure with suicidal ideation, suicide plans, and suicide attempts in military personnel and the general population in Canada. JAMA Psychiatry (2016) 73(3):229-38. doi:10.1001/jamapsychiatry.2015.2732

12. Woodruff T, Kelty R, Segal DR. Propensity to serve and motivation to enlist among American combat soldiers. Armed Forces Soc (2006) 32(3):353-66. doi: 10.1177/0095327X05283040

13. DeBellis MD. Developmental traumatology: thepsychobiologicaldevelopment of maltreated children and its implications for research, treatment, and policy. Dev Psychopathol (2001) 13(3):539-64. doi:10.1017/S0954579401003078

14. De Bellis MD, Hooper SR, Spratt EG, Woolley DP. Neuropsychological findings in childhood neglect and their relationships to pediatric PTSD. J Int Neuropsychol Soc (2009) 15:868-78. doi:10.1017/S1355617709990464 
15. McCrory E, De Brito SA, Viding E. Research review: the neurobiology and genetics of maltreatment and adversity. J Child Psychol Psychiatry (2010) 51:1079-95. doi:10.1111/j.1469-7610.2010.02271.x

16. McCrory EJ, De Brito SA, Sebastian CL, Mechelli A, Bird G, Kelly PA, et al. Heightened neural reactivity to threat in child victims of family violence. Curr Biol (2011) 21:R947-8. doi:10.1016/j.cub.2011.10.015

17. McLaughlin KA, Sheridan MA, Lambert HK. Childhood adversity and neural development: deprivation and threat as distinct dimensions of early experience. Neurosci Biobehav Rev (2014) 47:578-91. doi:10.1016/j.neubiorev.2014.10.012

18. McLean S. The Effect of Trauma on the Brain Development of Children. Evidence-Based Principles for Supporting the Recovery of Children in Care. (CFCA Practitioner Resource). Melbourne: Child Family Community Australia information exchange, Australian Institute of Family Studies (2016). Available from: https://aifs.gov.au/cfca/publications/effect-trauma-braindevelopment-children

19. Stavrou S, Nicolaides NC, Critselis E, Darviri C, Charmandari E, Chrousos GP. Paediatric stress: from neuroendocrinology to contemporary disorders. Eur J Clin Invest (2017) 47(3):262-9. doi:10.1111/eci.12724

20. Teicher MH, Samson JA. Annual research review: enduring neurobiological effects of childhood abuse and neglect. J Child Psychol Psychiatry (2016) 57(3):241-66. doi:10.1111/jcpp.12507

21. Sher L. Parental alienation: the impact on men's mental health. Int J Adolesc Med Health (Forthcoming). doi:10.1515/ijamh-2015-0083

22. Frodl T, O'Keane V. How does the brain deal with cumulative stress? A review with focus on developmental stress, HPA axis function and hippocampal structure in humans. Neurobiol Dis (2013) 52:24-37. doi:10.1016/j. nbd.2012.03.012

23. McEwen BS. Brain on stress: how the social environment gets under the skin. Proc Natl Acad Sci U S A (2012) 109:17180-5. doi:10.1073/pnas.1121254109

24. Hart H, Rubia K. Neuroimaging of child abuse: a critical review. Front Hum Neurosci (2012) 6:52. doi:10.3389/fnhum.2012.00052

25. Prasad MR, Kramer LA, Ewing Cobbs L. Cognitive and neuroimaging findings in physically abused preschoolers. Arch Dis Child (2005) 90:82-5. doi:10.1136/adc.2003.045583

26. Pollak SD, Nelson CA, Schlaak MF, Roeber BJ, Wewerka SS, Wiik KL, et al. Neurodevelopmental effects of early deprivation in post-institutionalized children. Child Dev (2010) 81:224-36. doi:10.1111/j.1467-8624.2009.01391.x

27. Carrion VG, Weems CF, Richert K, Hoffman BC, Reiss AL. Decreased prefrontal cortical volume associated with increased bedtime cortisol in traumatized youth. Biol Psychiatry (2010) 68(5):491-3. doi:10.1016/j.biopsych.2010.05.010

28. De Brito SA, Viding E, Sebastian CL, Kelly PA, Mechelli A, Maris H, et al. Reduced orbitofrontal and temporal gray matter in a community sample of maltreated children. J Child Psychol Psychiatry (2013) 54:105-12. doi:10.1111/j.1469-7610.2012.02597.x
29. Fisher PA, Lester BM, DeGarmo DS, Lagasse LL, Lin H, Shankaran S, et al. The combined effects of prenatal drug exposure and early adversity on neurobehavioral disinhibition in childhood and adolescence. Dev Psychopathol (2011) 23(3):777-88. doi:10.1017/S0954579411000290

30. Marshall DF, Passarotti AM, Ryan KA, Kamali M, Saunders EF, Pester B, et al. Deficient inhibitory control as an outcome of childhood trauma. Psychiatry Res (2016) 235:7-12. doi:10.1016/j.psychres.2015.12.013

31. Sher L, Yehuda R. Preventing suicide among returning combat veterans: a moral imperative. Mil Med (2011) 176(6):601-2. doi:10.7205/ MILMED-D-11-00026

32. Ogle CM, Rubin DC, Siegler IC. The impact of the developmental timing of trauma exposure on PTSD symptoms and psychosocial functioning among older adults. Dev Psychol (2013) 49(11):2191-200. doi:10.1037/ a0031985

33. Ogle CM, Rubin DC, Siegler IC. The relation between insecure attachment and posttraumatic stress: early life versus adulthood traumas. Psychol Trauma (2015) 7(4):324-32. doi:10.1037/tra0000015

34. Misiak B, Frydecka D. A history of childhood trauma and response to treatment with antipsychotics in first-episode schizophrenia patients: preliminary results. J Nerv Ment Dis (2016) 204(10):787-92. doi:10.1097/ NMD.0000000000000567

35. Cakir S, Tasdelen Durak R, Ozyildirim I, Ince E, Sar V. Childhood trauma and treatment outcome in bipolar disorder. J Trauma Dissociation (2016) 17(4):397-409. doi:10.1080/15299732.2015.1132489

36. Nelson J, Klumparendt A, Doebler P, Ehring T. Childhood maltreatment and characteristics of adult depression: meta-analysis. Br J Psychiatry (2017) 210(2):96-104. doi:10.1192/bjp.bp.115.180752

37. Sachs-Ericsson N, Cromer K, Hernandez A, Kendall-Tackett K. A review of childhood abuse, health, and pain-related problems: the role of psychiatric disorders and current life stress. J Trauma Dissociation (2009) 10(2):170-88. doi:10.1080/15299730802624585

38. Kendall-Tackett KA. Treating the Lifetime Health Effects of Childhood Victimization. Kingston, NJ: Civic Research Institute (2003).

Conflict of Interest Statement: The author declares that the research was conducted in the absence of any commercial or financial relationships that could be construed as a potential conflict of interest.

Copyright (c) 2017 Sher. This is an open-access article distributed under the terms of the Creative Commons Attribution License (CC BY). The use, distribution or reproduction in other forums is permitted, provided the original author(s) or licensor are credited and that the original publication in this journal is cited, in accordance with accepted academic practice. No use, distribution or reproduction is permitted which does not comply with these terms. 